\title{
Innovative Approach in Acoustic Simulation of Timber Walls
}

\author{
Marco Caniato $^{1}$, Paolo Bonfiglio ${ }^{2}$, Federica Bettarello ${ }^{3}$, Andrea Gasparella ${ }^{1}$ \\ ${ }^{1}$ Free University of Bozen, Faculty of Science and Technology, Bozen, Italy \\ ${ }^{2}$ Materiacustica srl, Ferrara, Italy \\ ${ }^{3}$ University of Trieste, Engineering and Architecture Department, Trieste, Italy
}

\begin{abstract}
The acoustic insulation performance of a glulam system (timber-framed wall) is of paramount importance in sustainable lightweight constructions. Nevertheless, traditional models like impedance coupling or double-leaf theory cannot offer robust results comparable to measurements. Even Finite Element (FE) simulations may not provide good results, due to high variables computations models and the resultant error propagation.

For these reasons, in this paper the Transfer Matrix Modelling (TMM) method has been adopted tor the acoustic analysis of glulam timber structures in order to understand its advantages and limitations. The sound insulation of glulam walls will be simulated using a decoupled approach where beams will be considered as linear sound bridges.
\end{abstract}

\section{Introduction}

In recent years, the number of wooden constructions has been growing, thanks to a change in the awareness of designers, builders and end users. Timber buildings can be cost effective, store $\mathrm{CO}_{2}$ and are based on a sustainable, renewable and non-polluting material, neither for production nor for final disposal.

It was recently demonstrated by Ramage et al. (2017) that wood for construction is one of the many forest products around the world.

However, such constructions are not and cannot be approached in the same way as traditional heavy bricks or concrete because (i) the construction technologies are profoundly different, (ii) the design follows different lines of thought and (iii) the attainable performances can be different, especially in the acoustic domain. For example, the results of the COST action FP90702 (2012) led to the conclusion that timber frame constructions provide better acoustic insulation in mid- and high-frequency but worse in low-frequency than traditional heavy constructions.

In this perspective, also the design and performance forecasting tools of these constructions must evolve and adapt to the wooden constructions and their particularities.

Moreover, nowadays there is need for increasingly accurate and detailed forecasts of the behavior of individual components and to be able to optimize the composition directly within the same analysis tool, without having to run multiple tools and combine results together.

Available methodologies for acoustic simulation of transmission loss are the following:

1. Empirical or semi-empirical models

2. Statistical Energy Analisys (SEA)

3. Finite Element Method (FEM) or Analisys (FEA)

4. Progressive impedance method

5. Transfer Matrix Method.

The first ones are very related to single compositions and could not include variations (Mak and Wang, 2015). For example equations are available for dedicated cases such as double-leaf masonry partitions valid for $80 \leq \mathrm{m}^{\prime} \leq 400$ $\left[\mathrm{kg} / \mathrm{m}^{2}\right]$ and for a maximum air gap thickness of $5 \mathrm{~cm}$ or plasterboard with an upper limit of $\mathrm{m}^{\prime} \leq 150\left[\mathrm{~kg} / \mathrm{m}^{2}\right]$, etc. Moreover, the majority of these models do not provide frequency information but just indexes, and this prevents to know if there will be noise caused by timber structures.

For the second and third ones, recent works managed to solve the problem using SEA (Kouyoumji, 2013; Kouyoumji and Guigo, 2015; Wang and Rajaram, Kouyoumji, 2015), FEM analysis (Mahn and al., 2014), or FEA analysis (Henning et al., 2013) models trying to cover other possibilities. However, these methodologies are always related to single specific configurations or to specific frequencies and cannot be generalized to other configurations.

The progressive impedance theory (Fringuellino and Guglielmone, 2000) generalizes the problem, starting from the materials properties and including the $2 \mathrm{D}$ wave propagation, considering constant and homogeneous the material properties for single layer. This method defines the surface acoustic impedance parameter defined as follows:

$$
z_{1}=\mathrm{Zc} \frac{-i z_{2} \cot \left(k_{c} \mathrm{l}\right)+z_{c}}{z_{2}-i z_{c} \cot \left(k_{c} \mathrm{l}\right)}
$$

where $z_{1}$ and $z_{2}$ are the surface impedances at respectively $\mathrm{x}=0$ and $\mathrm{x}=1$ of a layer (Figure 1 ), $Z_{c}$ is the complex impedance for dissipating materials and $\mathrm{k}_{\mathrm{c}}$ is the complex wave number. 


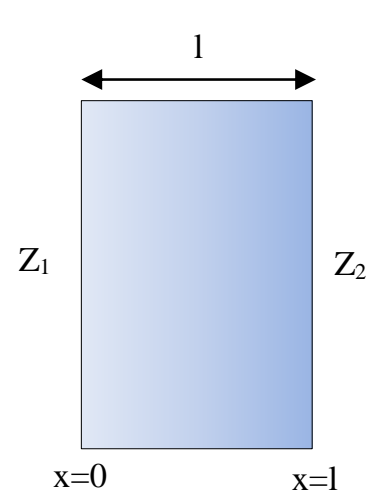

Figure 1: homogenous material layer.

If this model is applied to multi-layered systems (Figure 2 ), equation (1) is used for each individual interface and generalized in the following equation:

$$
z_{i}=z_{c} \frac{-i z_{i-1} \cot \left(k_{c}^{i} l_{i}\right)+z_{c}^{i}}{z_{i-1}-i \mathrm{z} \cot \left(k_{c}^{i} l_{i}\right)}
$$

where $l_{i}$ are the thickness of every element constituting the composition.

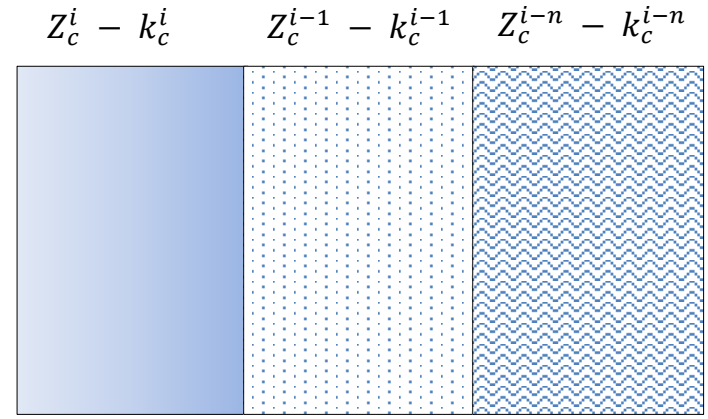

Figure 2: Progressive impedance method scheme.

This method is widely utilized for systems involving porous or fibrous materials and in general for composite systems, used in the field of sound absorption. However, when the method is applied to transmission loss, the results are not always reliable because they tend to under or overestimate the impedance for continuous materials such as wood, metals, etc.; Furthermore, it fails to take into account any resonances of the system (Mak and Wang, 2015) or rigid or viscoelastic connections present in the composition (Allard and Atalla, 2009).

The last method deals with a mathematical matrix approach where many dedicated models could be introduced when needed and solved in an all-inclusive model (Figure 3).

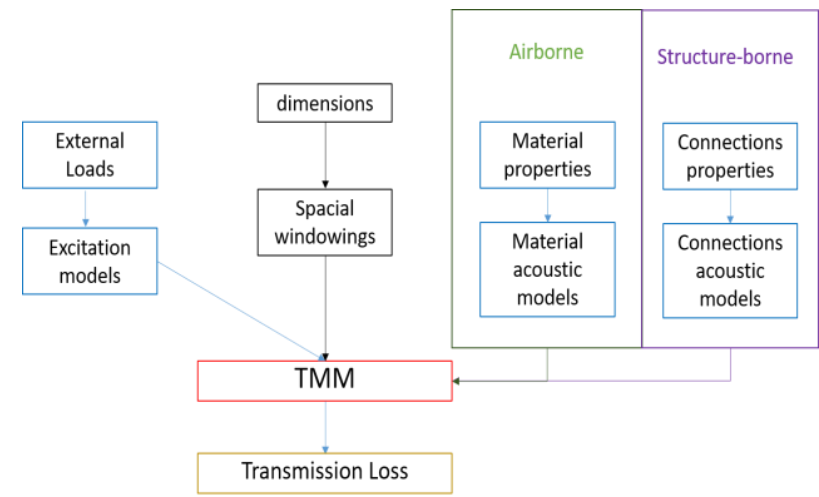

Figure 3: TMM functional scheme.

More specifically, TMM generally solves a twodimensional problem related to the impact of a flat acoustic wave on the surface of a structure composed of two or more layers (Figure 4). In general, the method can be described analytically as follows:

$$
\mathrm{V}\left(\mathrm{S}_{1}\right)=[\mathrm{T}] \mathrm{V}\left(\mathrm{S}_{2}\right)
$$

The vector $\mathrm{V}\left(\mathrm{S}_{1}\right)$ represents all the variables necessary to define the acoustic indicators (pressure, stresses, velocity, etc.) present on the surface $S_{1}$, while the vector $V\left(S_{2}\right)$ contains the same descriptors for the surface $S_{2}$. Elements of matrix $\mathrm{T}$ depend on physical and mechanical parameters relative to each specific layer.

In other words, the transfer matrix [T] describes the full transmission of sound waves through the layered structure. The size of this matrix depends on the nature of each layer, such as solid, fluid, poroelastic or viscoelastic. The materials within the various coupled layers are assumed in the first instance to be infinite in the lateral parts, but in this way there could be significant differences between the measured values and those simulated, especially at low frequency. This has been avoided by using the window with finite limitations (Bonfiglio et al. 2016, Santoni et al., 2017).

Assuming that the layered structure is enveloped in a semi-infinite fluid on both sides, it is possible to describe the relationship between the complex transmission $\mathrm{T}$ and the reflection coefficient $R$ as:

$$
T=-(1+R) \frac{\operatorname{det}[(D n+1)]}{\operatorname{det}[D 1]}
$$

being $\left[D_{n+1}\right]$ and $D_{1}$ matrices obtained from a complete matrix D (combination of transfer matrix of each layer, coupling matrices and proper boundary conditions) once columns $n+1$ and 1 have been deleted.

The complex reflection coefficient is defined as follows:

$$
R=\frac{Z_{S} \cos \theta-Z_{0}}{Z_{S} \cos \theta+Z_{0}}
$$

where $Z_{0}=\rho_{0} c_{0}$ represents the characteristic impedance of the fluid. This is a function of density $\rho_{0}$ and speed of sound $\mathrm{c}_{0}$

$\mathrm{Z}_{\mathrm{s}}$ represents instead the surface impedance of a layer of the package considered and can be calculated as follows:

$$
Z_{s}=-\frac{\operatorname{det}\left[D_{1}\right]}{\operatorname{det}\left[D_{2}\right]}
$$


$\mathrm{p}_{\mathrm{i}}$

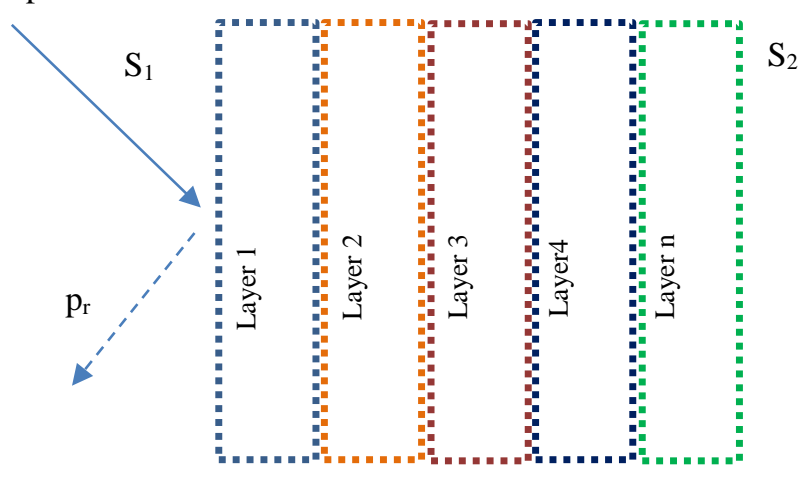

Figure 4: Sound wave pi impacting on a multi-layered structure

This research aims to test and validate numerical simulations by using the Transfer Matrix Model (TMM) applied to wooden walls with frame technology, resulting in the apparent sound insulation index R (Transmission Loss TL) in frequency. The limits of this method are then investigated both as regards frequency and complexity of composition.

\section{Motivation of the study}

Acoustic simulations for the determination of parameters such as apparent sound insulation are traditionally based either on simple mathematical models such as progressive impedance, or on predictive formulas derived from physical or empirical models (Mak and Wang, 2015). These formulas are derived from the experience of laboratory or in situ measurements of many partitions.

Traditional finite element (FEM or FEA) or statistical (SEA) simulation techniques are rarely used in the field of sound insulation, because the complexity of the structures involved and the diversity of materials, combined with the presence of multiphysical phenomena such as fluid dynamics coupled with the mechanics, actually frustrate the possibility of using these methods (Yu et al. 2018). In fact, if results have to be reliable, the computational times, given the presence of many nodes and the consequent propagation of the error, are unacceptable. Moreover, they are typically obtainable only from low to medium frequencies.

At higher ranges, with the increase of available energy and therefore of the stimulus for each node, the current models are not able to respond accurately.

Moreover, such methods do not allow an easy and fast improvement and optimization of the composition of the building component. They rather require redrawing it completely or in part, starting again the simulation from the initial stage. This means to recreate all the degrees of freedom, regenerate and refine the mesh and apply all the loads again. These procedures are time consuming and imply lots of computational time. For these reasons, more effective alternative methods such as TMM need to be studied and validated. This method has the advantage of not having to completely redesign the geometry of the sample and of being able to include dedicated analytical methods focused on specific cases (Munjal, 1993; Allard and Atalla, 2009). Based on TMM scheme (Figure 3), it is clear that if it is needed to add another layer or to modify an existing one, it could be simply implement the associated matrix on the correct step of the model.

This approach has already been applied to metal framestructures and also to plasterboard double leaves walls and massive partitions (Sharp, 1978, Vigran, 2010).

Traditional methods like progressive impedances cannot take into account effectively solid junctions as example or cannot easily model differences for porous or poroelastic materials.

TMM was successfully used for multi-layered infinite plate (Munjal, 1993), finite stiffened and orthotropic structures lined by porous materials in a multi-layered configuration (Ghinet and Atalla, 2001), double fiberboard partitions and sandwich structures (Dijckmansa and Vermeir, 2010; Piana et al., 2014) sound absorption forecasting (Verdière et al., 2013), ETHICS influence on masonry wall (Santoni et al. 2017), but no application to glulam partitions is currently available. Some recents studies (Santoni et al., 2017b; Santoni et al., 2018) dealt with the TMM simulation of cross-laminated timber walls.

There is therefore a need to understand whether TMM is able to provide reliable results for prefabricated wooden partitions with respect to the apparent sound insulation index that these structures can offer. The simulated results were then compared to laboratory measured ones.

In addition, the ease of implementation of the model in the case of TMM allows a parametric analysis of the individual components and the evaluation of different layer combinations even much more complex.

\section{Materials and methods}

In this work, a numerical model is applied for the determination of the influence of materials on the propagation of the acoustic wave.

\section{Investigated structure}

In order to understand if the method described above can be applied to stratified wooden partitions with inner frame structure, we have proceeded to identify a traditional partition related to this type of construction and consisting of the following (Figure 5) elements:

- OSB panel, thickness $2.2 \mathrm{~cm}$

- Wooden beams $16 \mathrm{~cm}$ thick and $8 \mathrm{~cm}$ wide

- Filling in mineral wool $16 \mathrm{~cm}$ thick and density 40 $\mathrm{kg} / \mathrm{m}^{3}$

- OSB panel, thickness $1.4 \mathrm{~cm}$ 


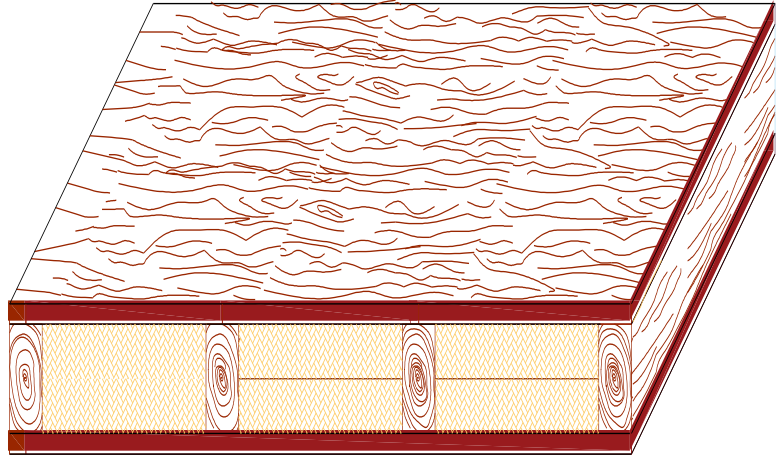

Figure 5: Studied structure.

In order to obtain an experimental result, this partition was tested in laboratory according to the series of standards ISO 10140:2010. This procedure was useful to study the frequency behavior of partition transmission loss, to understand the robustness and reliability of the model and to validate the numerical simulation and the assumptions related to it. The real timber frame partition was mounted in laboratory (coupled chambers) and an airborne omnidirectional noise source was used to excite the sample.

In order to investigate which model could be more suitable to be adapted to the different partition components, various simulation steps were taken:

(i) only the single OSB panel is considered, in order to investigate its frequency behavior both as isotropic and orthotropic panel;

(ii) once defined the elastic properties of the external shells (OSB), the partition is modelled as if the rigid connections between the two external panels were not present;

(iii) the structural connections are inserted.

In all the previous phases, the OSB panels are considered elastic solids.

In (iv), the OSB panels are considered as viscoelastic materials (Figure 3).

OSB mechanical properties are reported in Table 1.

Mineral fiber was modelled as poroelastic medium using Johnson- Champoux-Allard (JCA) model (Allard and Atalla, 2009). This model requires the knowledge of five physical and geometrical parameters (namely, airflow resistivity, open porosity, tortuosity and viscous and thermal characteristic lengths). According to this model, the porous material can be replaced on a macroscopic scale by an equivalent fluid of effective density $\rho$ and effective bulk modulus $\mathrm{K}$. The motionless frame condition can occur either because of high density or elasticity modulus, or because of particular test conditions (i.e. material placed on a rigid wall). The viscous effects and thermal exchanges can be treated separately. In Table 2 the used parameters and related values for the JCA model are reported for a rock wool (density $40 \mathrm{~kg} / \mathrm{m}^{3}$ ).
Table 1: Used parameter for OSB layer $\left(\rho=700 \mathrm{~kg} / \mathrm{m}^{3}\right)$.

\begin{tabular}{cccccc}
\hline Material & $\mathbf{E}_{1}[\mathbf{G P a}]$ & $\begin{array}{c}\mathbf{E}_{\mathbf{2}} \\
{[\mathbf{G P a}]}\end{array}$ & $\begin{array}{c}\mathbf{G} \\
{[\mathbf{G P a}]}\end{array}$ & $\mathbf{v}$ & $\eta$ \\
\hline $\begin{array}{c}\text { OSB } \\
\text { isotropic }\end{array}$ & 3.8 & -- & 1 & 0.2 & 0.1 \\
\hline OSB & 3.8 & 3 & 1 & 0.2 & 0.1 \\
orthotropic & & & & & \\
\hline OSB & $\begin{array}{c}\text { Depends on } \\
\text { frequency } \\
\text { Visco }\end{array}$ & 1 & 0.2 & 0.1 & \\
elastic & see Figure 6 & & & & \\
\hline
\end{tabular}

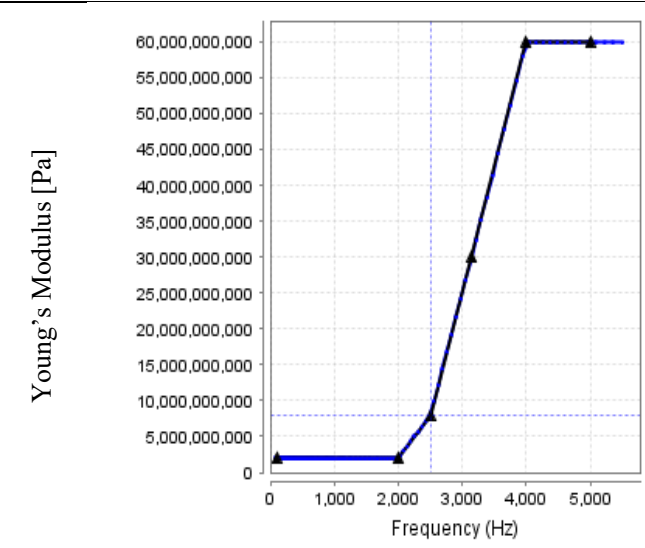

Figure 6: Elastic modulus E [Pa] as a function of frequency for the OSB panel.

Table 2: Used parameter for poroelastic material, obtained by inversion from a Kundt tube measurement.

\begin{tabular}{cccccc}
\hline Material & $\sigma$ & $\phi$ & $\alpha$ & $\Lambda$ & $\Lambda^{\prime}$ \\
\hline Rock wool & 15400 & 0.98 & 1.04 & $56 \mathrm{e}-6$ & $11 \mathrm{e}-6$
\end{tabular}

where $\rho$ is the density $\left[\mathrm{kg} / \mathrm{m}^{3}\right] \sigma$ is the airflow resistivity $\left[\mathrm{Ns} / \mathrm{m}^{4}\right], \phi$ is the open porosity, $\alpha$ is the tortuosity, $\Lambda$ is the viscous length [m] and $\Lambda^{\prime}$ is the thermal length [m].

Having the input parameters needed for the fluid phases, a JCA study was implemented in order to estimate the sound-proofing power $\mathrm{R}$ as a function of frequency.

The model used for the study is instead that of the linear connection with very high rigidity, because of the limited connection size compared to the length, with a distance between the linear connections in vertical of $60 \mathrm{~cm}$ and an internal damping $\eta$ equal to 0.1 .

\section{Results}

The apparent soundproofing test carried out in the laboratory is used as a basis for the validation of the model used. The frequency trend is shown in Figure 7, highlighting the typical resonance and coincidence zones for this type of partition. 
Experimental Transmission Loss

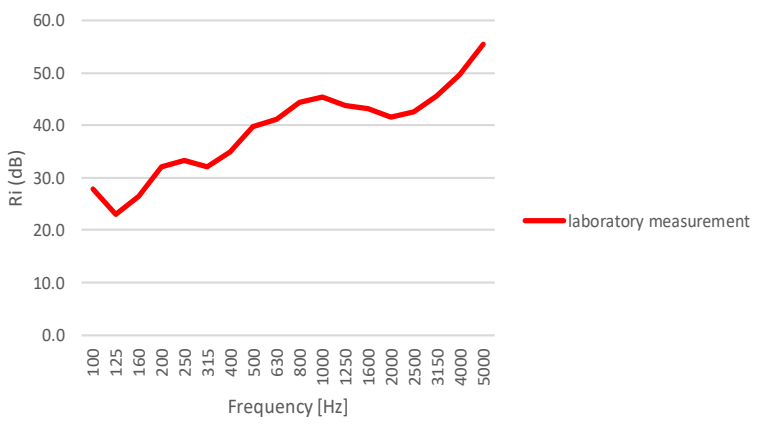

Figure 7: Transmission loss frequency trend of laboratory measurement.

Therefore, by carrying out numerical simulations using the method of transfer matrices, the frequency behavior of the various layers reported in the previous paragraph was investigated. In Figure 8, the frequency trends of the results of the numerical simulations carried out exclusively with a single OSB panel are reported.

Comparing the frequency trends with those measured experimentally, we can see that the orthotropic trend is not representative of the real model, because the coincidence phenomenon occurs at lower frequencies than those found in the laboratory test. On the other hand, the results provided by the simulation of the isotropic model show how coincidence occurs at levels comparable to those measured experimentally. For this reason, in step (ii), the isotropic model has been maintained for the two external shells.

In Figure 9 is instead reported the frequency trend of the results of the simulation operated by inserting the linear structural connections (iii) (infinite stiffness, massless), separating the contribution of the airborne sound transmission from the structural one.

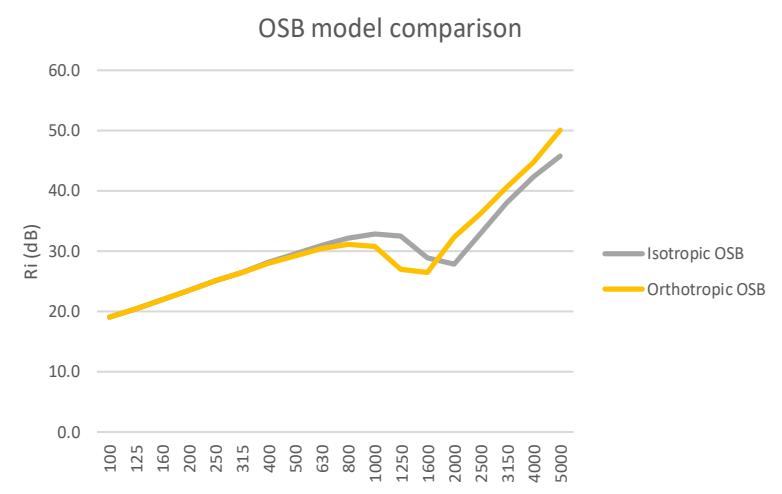

Figure 8: Numerical simulations for different $O S B$ models.

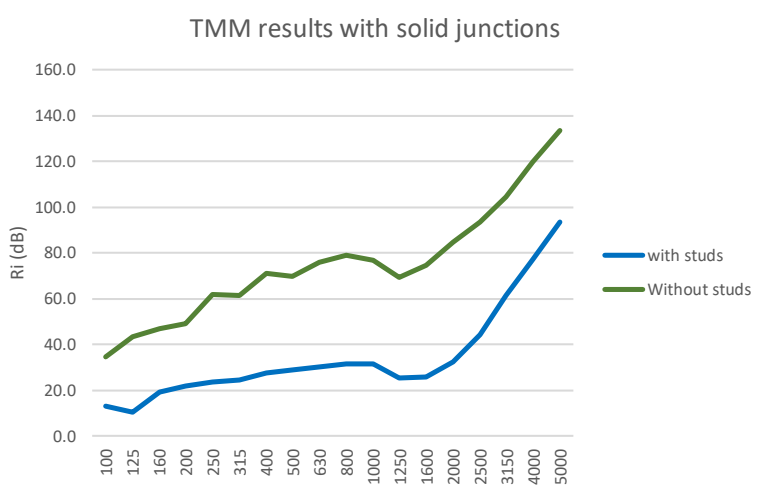

Figure 9: numerical simulations complete partition taking into account rigid connections.

As is evident, the most important part is represented by the influence of structural connections that effectively overcome airborne sound transmission. The final result, represented by the energy sum of the two curves, clearly coincides with the structural part.

The latter simulates fairly correctly the frequency behavior of the real wall up to about $1600 \mathrm{~Hz}$. After this frequency, the influence of the rigidity of the OSB panels intervenes in the propagation by raising the curve of the sound insulation index to non-real values.

To overcome this inconvenience, a frequency-dependent behavior, linked to OSB panels, was used is reported in Figure 6.

In Figure 10, the trend of the complete partition is reported with the addition of the viscoelastic model for the OSB panels and compared with the experimental data.

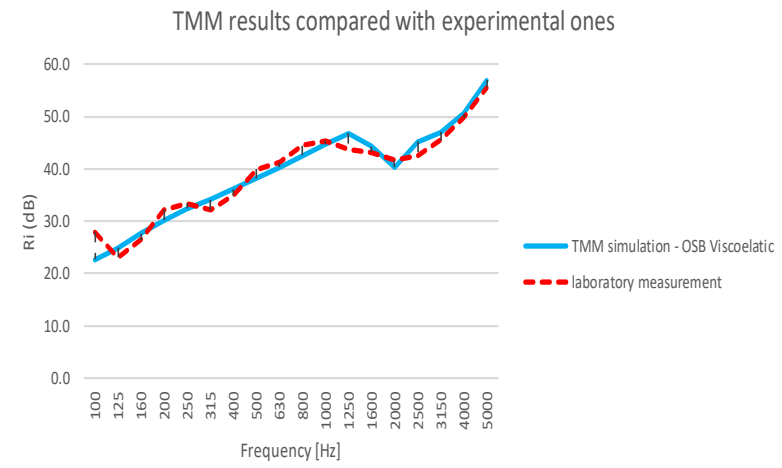

Figure 10: Numerical simulations for the partition with rigid connections and use of the visco-elastic model for OSB panels. Comparison with experimental data.

\section{Discussion}

In this work, a numerical simulation procedure was presented using transfer matrices and adapting the model itself to a composite partition made up of wood and mineral fiber, with the presence of an internal frame. The aim of the research is to understand the limits of the method and its possible implementations for numerical simulation in the field of wooden frame structures.

The results presented show how the method can provide reliable and robust results. 
In order to understand how this method is more reliable for this type of application than traditional ones, (progressive impedances), in Figure 11 the comparison between progressive impedance obtained using one of the state-of-the-art commercial software for building acoustics and TMM is reported, highlighting the big difference in frequency trend result. Furthermore, as demonstrated by equation (2), in progressive impedance method it is not possible to investigate the sound propagation influence while for TMM (Figure 3, equations (3)-(6), Figure 9) it is possible to investigate also the influence of the propagation path as part of a parameter study.

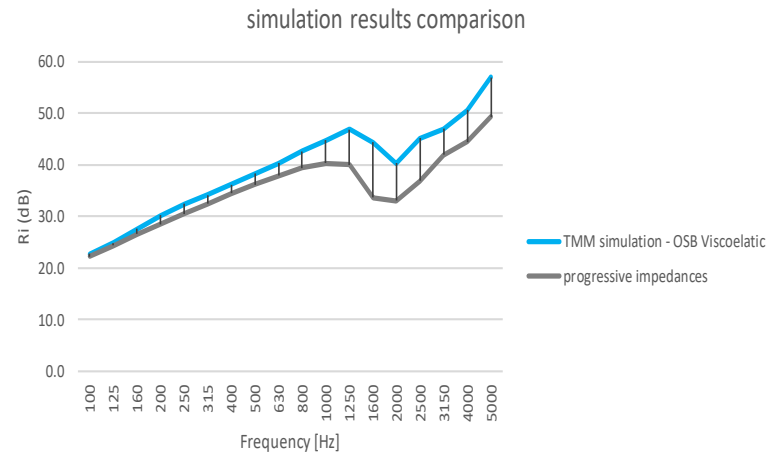

\section{Figure 11: numerical simulations complete partition} taking into account different model.

In this view, the isotropic or orthotropic nature of the OSB panel could be investigated and it was concluded that the first one could come closer to the final performance of the partition. However, maintaining the isotropic or orthotropic model, at medium-high frequencies the dissipative effects inside it are negligible. This is the reason why it was introduced the viscoelastic model to better simulate this layer. This behavior is explained by the intrinsic composition of the OSB panel, composed of wooden chips pressed and glued together by a thermoplastic polymer. The related literature (Benkreira, et al. 2011; Sun et al., 2013) agrees that the dissipative viscoelastic effect of the polymer, which acts as a matrix, has a very important role on the propagation of the wave within recycled materials. In this case, the present research is fully in agreement with the previous work on this subject, demonstrating that recycled materials cannot be modelled in acoustic simulations as homogeneous layers.

Another important result of this approach is related to the parameterization of the study, which can then provide information on the individual actors taking part in the propagation of the wave within the composite partition.

As demonstrated in Figure 9, the partition could be extremely performing if it did not include the structural connections passing from one side to the other. In fact, airborne sound insulation could potentially reach extremely high transmission loss values in frequency, being governed exclusively by the mass-spring-mass phenomenon.
However, when rigid structural connections are added across the entire partition thickness, the performance drops by up to $60 \mathrm{~dB}$ due to solid propagation. In this case, neither the mass of the connection nor its stiffness is very important; in this case, in fact, it has been set with a very high value, as the wooden beams are very thin compared to their length; furthermore, they present in reality a high transverse elastic modulus and a consequent excellent transmission of the sound wave. (Bucur et al., 2002; Beall, 2002; Bucur, 2006).

For this reason, associating a viscoelastic behavior to the two OSB panels, it is possible to obtain a frequency behavior similar to the measured ones.

In addition, the study was able to show how, without predefined databases, the transmission loss of complex wooden structures can be calculated with good reliability. The use of the TMM method has shown to be the possibility to study the partition parametrically, in good agreement with past research (Brunskog and Hammer, 2003a; Brunskog and Hammer, 2003b, Fortini et al., $2019)$; it may therefore provide a very powerful tool for deepening and characterization of the acoustic performance of this type of partitions.

Moreover, as already highlighted by many research projects such as Kouyoumji (2015) or Brunskog and Hammer (2000), the importance of having an instrument that, after appropriate calibrations, can provide the most precise forecast of the acoustic performance of complex walls, presents itself as a strong possibility for the research, design, implementation and construction of increasingly complex and performing wooden structures. The limits of this method lie exclusively in the deep knowledge of the physical mechanisms that govern the propagation of the acoustic wave in the different materials and couplings between them, as well as the possibility of measuring or finding in the literature reliable data relating to the mechanical and acoustic characteristics inherent in the materials. In fact, it has been demonstrated that the model variation of the OSB panel alone involves or does not involve obtaining a final result in accordance with the experimental one.

\section{Conclusion}

A prediction model, developed to investigate the transmission loss provided by timber frame partitions, has been presented. All the factors necessary for numerical simulation have been described and their parametric influence has been discussed and argued.

The results provided by the model based on transfer matrices (TMM) were then validated by a laboratory measurement of the partition itself, finding an excellent agreement between two frequency trends.

It has been demonstrated that the method presents the best frequency results, also compared to progressive impedances ones, and that it could provide parametrical investigations on every step of the analysis highlighting paramount effects:

1. isotropic behaviour of external panel and its consequence on coincidence, 
2. viscoelastic influence of OSB panels at middle-high frequencies,

3. predominant sound wave path transmission through solid junctions.

In the future, new simulations will be carried out by adding different layers to the test partition used in this research work, focusing on ETICS rather than additional internal layers, to understand how far this innovative way of simulating the transmission loss of a framed wooden partition can be taken.

\section{Acknowledgement}

This work was financed by EFRE 2014-2010 1095 E21@NOI CUP D56C18000180009 and by "Klimahouse and energy production" in the framework of the programmatic-financial agreement with the Autonomous Province of Bozen-Bolzano of Research Capacity Building, which are gratefully acknowledged.

\section{Authors' Contributions}

Marco Caniato and Federica Bettarello developed the research. Marco Caniato defined the methods and comparisons. Marco Caniato and Paolo Bonfiglio performed the numerical simulations and the experimental measures. Marco Caniato and Federica Bettarello described potential future developments. Andrea Gasparella overviewed and supervised the research. Marco Caniato wrote the paper.

\section{References}

Allard, J., Atalla N. (2009). Propagation of sound in porous media: modelling sound absorbing materials. 2nd ed. Chichester, UK: John Wiley \& Sons, Ltd

Beall, FC. (2002). Overview of the use of ultrasonic technologies in research on wood properties. ood Science and Technologies, 36, pp. 197-212

Benkreira, H., Khan, A., Horoshenkov, K.V. (2011).Suistainable acoustic and thermal insulation materials from elastomeric waste residues, Chemical Engineering Science, 66, pp.4157-4171

Bonfiglio, P., Pompoli, F., Lionti, R., (2016) A reducedorder integral formulation to account for the finite size effect of isotropic square panels using the transfer matrix method, Journal of Acoustic Society of America;139(4):1773. doi: 10.1121/1.4945717

Brunskog, J. and P. Hammer (2000). Prediction models of impact sound insulation on timber floor structures; a literature survey. Building Acoustics;7(2):89-112.

Brunskog, J. and P. Hammer (2003a). Design possibilities for impact noise insulation in lightweight floors - a parameter study. Proceedings of Euronoise, Naples (Italy).

Brunskog, J. and P. Hammer (2003b). Prediction model for the impact sound level of lightweight floors. Acta Acustica United with Acustisca 2003;89(2):309-22

Bucur, V., Lanceleur, P., Roge B. (2002). Acoustic properties of wood in tridimensional representation of slowness surfaces, Ultrasonics, 40:537-41
Bucur, V.(2006), Acoustics of wood, Springer, SpringerVerlag Berlin Heidelberg

COST action FP0702, (2012) Acoustic Design of Lightweight Timber Frame Construction, final ebook avialable http://extranet.cstb.fr/sites/cost/ebook/Forms/AllItem s.aspx (accessed on 22nd January 2019)

Dijckmansa, A. and G. Vermeir (2010). Sound transmission through finite lightweight multilayered structures with thin air layers, The Journal of the Acoustical Society of America 128, 3513 (2010); https://doi.org/10.1121/1.3500698

Fortini, M., Granzotto, N., Piana, E.A. (2019). Vibroacoustic characterization of a composite structure featuring an innovative phenolic foam core, Applied Sciences Volume 9, Issue 7, Article number 1276. DOI: $10.3390 /$ app9071276.

Fringuellino, M. and C. Guglielmone (2000). Progressive Impedance Method for the classical analysis of acoustic transmission loss in multilayered walls, Applied Acoustics Volume 59, Issue 3, Pages 275-285

Ghinet, S. and N. Atalla, (2001). Sound Transmission Loss of Insulating Complex Structures, Canadian Acoustics / Acoustique canadienne Vol. 29 No. 3 - 26

Henning, P., Kirkegaard, L., Vabbersgaard A. (2013). FEA of the variations in sound insulation in nominally identical prefabricated lightweight timber structures, Procedings of Internoise, Innsbruck (AUSTRIA) 1518 September

Kouyoumji J.L. and C. Guigou (2015). Predicting sound transmission loss of timber framed walls and floors using SEA, in "AcuBois" project of the French wood industry Proceedings of Internoise, San Francisco (US) 9-12 August.

Kouyoumji J.L. (2013). Prediction sound transmission loss on lightweight timber framed construction using sea, Proceedings of Internoise, Innsbruck (AUSTRIA) 15-18 September

Kouyoumji J.L. (2015). Predicting Sound Transmission Loss of timber framed walls and floors using SEA, in "AcouBois" project of the French wood industry, Proceedings of Internoise, San Francisco (USA) 9-12 Agoust

Mahn, J., Hopkins, C., Filippoupolitis, M., Schanda, U., Völt, R., Krajči, L. (2014). The optimization of a wooden floor design based on validated finite element models, Procedings of Internoise, Melbourne (Autralia), 16-19 november

Mak C.M. and Z. Wang (2015). Recent advances in building acoustics: An overview of prediction methods and their applications, Building and Environment, Volume 91, Pages 118-126

Munjal M. (1993). Response of a multi-layered infinite plate to an oblique plane waveby means of transfer 
matrices Journal of Sound and Vibration;162(2):33343

Piana, E., Milani, P., Granzotto, N. (2014). Simple method to determine the transmission loss of gypsum panels, Proceeding $s$ of 21st International Congress on Sound and Vibration 2014, ICSV 2014; Beijing; China; Volume 5, 2014, Pages 3700-3706.

Ramage M. H., Burridge H., Busse-Wicher M., Fereday G., Reynolds T., Shah D. U., Wu G., Yu L., Fleming P., Densley-Tingley D., Allwood J., Dupree P., Linden P.F., Scherman O. (2017). The wood from the trees: The use of timber in construction, Renewable and Sustainable Energy Reviews, Volume 68, Part 1, Pages 333-359

Santoni A., Bonfiglio P., Davy J. L., Fausti P., Pompoli F., Pagnoncelli L. (2017a). Sound transmission loss of ETICS cladding systems considering the structureborne transmission via the mechanical fixings: Numerical prediction model and experimental evaluation, Applied Acoustics 122 88-97

Santoni, A. Bonfiglio, P., Fausti, P., Schoenwald, S., (2017b). Predicting sound radiation efficiency and sound transmission loss of orthotropic crosslaminated timber panels, Proceedings of Meetings on Acoustics, 173EAA; 30: p. 015013

Santoni, A. Bonfiglio, P., Mollica, F., Fausti, P., Pompoli, F., Mazzanti V. (2018). Vibro-acoustic optimisation of Wood Plastic Composite systems, Construction and Building Materials, 174: 730-740.
Sharp B. H. (1978). Prediction methods for the sound transmission of building elements.Noise Control Engineering, 11(2): 53-63.

Sun Z., Shen Z., Ma S., Zhang X. (2013). Novel Application of Glass Fibers Recovered From Waste Printed Circuit Boards as Sound and Thermal Insulation Material, Journal of Materials Engineering and Performance, Volume 22, Issue 10, pp 3140-3146

Vigran, T. E. (2010). Sound transmission in multilayered structures-introducing finite structural connections in the transfer matrix method. Appl Acoust;71 (1): 3944.

Verdière, K., Panneton, R., Elkoun, S. (2013). Transfer matrix method applied to the parallel assembly of sound absorbing materials, The Journal of the Acoustical Society of America 134, 4648; https://doi.org/10.1121/1.4824839

Wang, T., Li, S., Rajaram, S., Nutt, (2010). Predicting the sound transmission loss ofsandwich panels by statistical energy analysis approach, Journal of Sound and Vibration 132(1):1-7.

Yu, X., Zhang, Q., Kang, J., Cui, F. (2018). Predicting integrated thermal and acoustic performance in naturally ventilated high-rise buildings using CFD and FEM simulation, Building Simulation 11(3), pp. 507518 